\title{
Impacto da pandemia da covid-19 na produção e consumo de hortaliças no sudeste do
}

\section{Pará}

\author{
Impact of the covid-19 on the production and consumption of vegetables in southeast Pará
}

Impacto de la pandemia covid-19 em la producción y consumo de verduras em el sureste de Pará

Recebido: 05/06/2021 | Revisado: 16/06/2021 | Aceito: 17/06/2021 | Publicado: 02/07/2021

Elisandra Silva Canela

ORCID: https:// orcid.org/ 0000-0002-9864-8192 Universidade Federal do Sul e Sudeste do Pará, Brasil E-mail: elisandrasilvacanela0@gmail.com

Ester da Silva Criança

ORCID: https:// orcid.org/0000-0001-9915-3610 Universidade Federal do Sul e Sudeste do Pará, Brasil E-mail: esterdasilvacrianca@gmail.com

Caroline Nebo

ORCID: https://orcid.org/0000-0003-3553-956X Universidade Federal do Sul e Sudeste do Pará, Brasil E-mail: carolnebo@unifesspa.edu.br

\begin{abstract}
Resumo
O objetivo do trabalho foi avaliar o perfil dos produtores de hortaliças e consumidores nos municípios de Xinguara e Rio Maria do estado do Pará. Questionários semiestruturados foram utilizados nas entrevistas que foram realizadas no formato remoto em diferentes plataformas digitais. A maior parte dos produtores rurais dos municípios entrevistados são homens (70\%), acima de 31 anos de idade, atuam na agricultura a mais de seis anos e trabalham entre cinco a oito horas/dia no cultivo de vegetais, sendo que a maioria reside dentro do perímetro urbano. A produção verduras folhosas prevalece, sendo que $80 \%$ dos entrevistados utilizam menos de um hectare da área para o plantio no sistema semiintensivo e comercialização principal nas feiras-livres. A pandemia da Covid-19 interferiu na produção e comercialização em $80 \%$ dos produtores rurais com diminuição entre $10 \%$ a $70 \%$. A frequência de compra de hortaliças pelos entrevistados é de uma vez na semana, sendo nos finais de semana os dias escolhidos para adquirir produtos mais frescos. Os vegetais mais consumidos são a alface, couve, cebolinha, coentro e tomate e as compras realizadas preferencialmente nos períodos da manhã, nos supermercados e o gasto médio familiar até $\mathrm{R} \$ 30,00$ reais/semana. $\mathrm{O}$ preço e qualidade estão entre os requisitos mais importantes na aquisição dos produtos. Com a pandemia da Covid-19, a maior parte dos consumidores não deixaram de consumir hortaliças, porém uma pequena parcela dos entrevistados tive que reduzir em até $10 \%$ do consumo devido a diminuição da renda familiar.
\end{abstract}

Palavras-chave: Agricultura familiar; Frequência de consumo de vegetais; Segurança alimentar.

\begin{abstract}
The aim of this study was to evaluate the profile of vegetable producers and consumers in the cities of Xinguara and Rio Maria in the state of Pará. Semi-structured questionnaires were used in the interviews that were carried out in remote format on different digital platforms. Most vegetable farmers in the counties interviewed $70 \%$ are men, over 31 years of age, have been working in agriculture for more than six years and work between five to eight hours/day growing vegetables, with the majority residing within the urban perimeter. The production of leafy vegetables prevails, with $80 \%$ of those interviewed using less than one hectare of the area for planting in the semi-intensive system and mainly commercialized at open-air markets. The Covid-19 pandemic interfered in production and marketing in $80 \%$ of rural producers, with a decrease between $10 \%$ and $70 \%$. The frequency of purchase of vegetables by respondents is once a week, with weekends being the days chosen to purchase fresher products. The most consumed vegetables are lettuce, cabbage, chives, cilantro and tomato, and purchases are preferably made in the morning, in supermarkets, and the average family expense is up to $\mathrm{R} \$ 30.00 /$ week. Price and quality are among the most important requirements when purchasing products. With the Covid-19 pandemic, most consumers did not stop consuming vegetables, but a small portion of respondents had to reduce consumption by up to $10 \%$ due to the decrease in family income.
\end{abstract}

Keywords: Family farming; Frequency of vegetables consumption; Food security.

\section{Resumen}

El objetivo de este estudio fue evaluar el perfil de productores y consumidores de hortalizas en las ciudades de Xinguara y Rio Maria en el estado de Pará. En las entrevistas se utilizaron cuestionarios semiestructurados que se realizaron en formato remoto en diferentes plataformas digitales. La mayoría de los productores de hortalizas en los condados 
entrevistados, $70 \%$ son hombres, mayores de 31 años, han estado trabajando en la agricultura durante más de seis años y trabajan entre cinco y ocho horas diarias cultivando hortalizas, la mayoría residiendo dentro del perímetro urbano. Predomina la producción de hortalizas de hoja, con el $80 \%$ de los entrevistados utilizando menos de una hectárea del área para la siembra en el sistema semi-intensivo y comercializada principalmente en mercados al aire libre. La pandemia Covid-19 interfirió en la producción y comercialización en el 80\% de los productores rurales, con una disminución entre el $10 \%$ y el $70 \%$. La frecuencia de compra de verduras por parte de los encuestados es una vez a la semana, siendo los fines de semana los días elegidos para adquirir productos más frescos. Las verduras más consumidas son la lechuga, la col, el cebollino, el cilantro y el tomate, y las compras se hacen preferentemente por la mañana, en los supermercados, y el gasto familiar promedio es de hasta R \$ 30,00 / semana. El precio y la calidad se encuentran entre los requisitos más importantes a la hora de adquirir productos. Con la pandemia de Covid-19, la mayoría de los consumidores no dejaron de consumir verduras, pero una pequeña parte de los encuestados tuvo que reducir el consumo hasta en un $10 \%$ debido a la disminución de los ingresos familiares.

Palabras clave: Agricultura familiar; Frecuencia de consumo de hortalizas; Seguridad alimentaria.

\section{Introdução}

O cultivo de hortaliças em pequena escala oriundo da produção de pequenos produtores é uma atividade com baixos índices de produção, pois geralmente é exercida com o pouco uso de tecnologia e pouca orientação de profissionais especializados. Segundo o censo agropecuário realizado pelo Instituto Brasileiro de Geografia e Estatística - IBGE (2012), no ano de 2006 o Brasil produziu cerca de 5.241,379 toneladas de hortaliças, isso levando em consideração as condições do produtor, produtos da horticultura, grupos de atividade econômica e área total produzida, sendo o tomate, alface, repolho, e cenoura os mais cultivados.

Em 2006, a agricultura familiar foi responsável pelo provimento de $70 \%$ dos alimentos consumidos e emprega cerca de $77 \%$ da mão de obra ativa no campo (IBGE, 2006). De acordo com o Anuário Brasileiro de Hortaliças (2014), a produção de vegetais foi de 19,4 milhões de toneladas e a agricultura familiar tem participação substancial nessa produção. No entanto, mesmo sendo o eixo de maior produção de alimentos à população brasileira, os agricultores ainda possuem fraquezas que travam de alguma forma a produtividade de suas propriedades, destacando-se a baixa escolaridade, pouca organização, ausência de gestão produtiva e dificuldade em atender as exigências sanitárias e ambientais vigentes (Alves et al. 2011; Carvalho \& Monteiro, 2015; IBGE, 2006).

Os pequenos produtores rurais, com os agricultores familiares possuem afinidade com a produção de hortaliças e para que se obtenham resultados economicamente viáveis e compensatórios não é necessária uma grande extensão de terras, como visto em outras produções agrícolas, como pouco conhecimento técnico. No entanto, é recorrente encontramos contaminações de diversas naturezas nas culturas de hortaliças, uma vez que, não seja adotado um rigoroso processo de cultivo que garanta não só a qualidade, como também a segurança dos alimentos. (Mattos et al. 2009).

Supoe-se que nos últimos dez anos a produção de vegetais tenha aumentado em $33 \%$ tendo a área plantada reduzida em $5 \%$, representando o aumento da produtividade em 38\%. A região Sudeste possui a maior concentração na produção acompanhada da região Sul, aproximadamente $60 \%$ da produção situa-se nas proximidades dos grandes centros consumidores, sendo chamados de cinturões verdes. São propriedades familiares com menos de 10 hectares, que são utilizados intensivamente (Silva et al. 2015).

A produção comercial, constitui-se de poucas variedades de hortaliças, uso de tecnologia e assistência profissional, garantindo assim a qualidade e alto rendimento da produção (Silva; Lopes; Magalhães; 2008). Nota-se que em diferentes locais do país há o emprego de novos perfis socioeconômico de produtores de hortaliças, que utilizam tecnologias mais precisas como sistemas computadorizados, “Global Positioning System” (GPS), cultivo protegido, fertirrigação, hidroponia, programas de manejo integrado de pragas e doenças, uso de sementes híbridas e/ou produtos geneticamente modificados (transgênicos), “mulching", onde é utilizado manta de plástico para cobertura do solo para proteger o cultivo e aumentar o teor de matéria orgânica no solo (Cruz et al. 2010). Para esse sistema utiliza-se resíduos orgânicos como folhas, serragem ou palha, e filme 
plástico especial. Porém o país apresenta características contrastantes em relação a produção agrícola, revelando diferenças enormes na adoção de insumos e uso de tecnologia. Mudanças de hábitos alimentares e a crescente demanda por alimentos mais saudáveis contribuiu para que os produtores mudassem a forma de produção e venda dos produtos, buscando atender e satisfazer ao desejo do consumidor (Freitas et al. 2017).

O uso da internet e redes sociais, vem promovendo mudanças no comportamento da população principalmente em relação à alimentação saudável. A maior exigência, por parte dos consumidores, ao adquirir produtos de consumo alimentar são questões como: contaminação, qualidade e origem que são cruciais para a decisão no ato da aquisição. Assim, a adoção das Boas Práticas Agrícolas (BPAs) são essenciais na produção de alimentos abrangendo desde a escolha do local para plantio até ao processamento na agroindústria incluindo a distribuição ao consumidor final (Mattos et al. 2009).

Quando se fala em boas práticas agrícolas, tempo e particularidade de produção, pensa-se logo na produção hidropônica, cujo o sistema de produção requer um tempo mínimo diferente de outros sistemas, a contaminação de solo e afluentes é inexistente se houver o manejo adequado do sistema, além de satisfazer as exigências do consumidor. A região Sudeste concentra o maior número de produções hidropônicas do país, em especial o estado de São Paulo, seguido das regiões Nordeste, Norte e região Sul (Sampaio et al. 1995).

Na região Norte, devido ao forte calor e a alta umidade do ar a produção é realizada em estufas climatizadas, destacandose as produções de alface, tomate, pepino, jambu e pimentão. $\mathrm{O}$ cultivo protegido traduz o ganho de eficiência produtiva, pois reduz o efeito da sazonalidade, além de se obter o controle de variáveis climáticas e possibilita a proteção contra pragas e doenças. Entretanto, esse tipo de produção requer um manejo adequado, na maioria das vezes as pragas e doenças estão associadas as práticas de manejo que criam um ambiente favorável para determinadas doenças (Silva et al. 2014).

Devido fatores econômicos, pequenos agricultores familiares utilizam de alternativas que viabilizem suas produções. Uma das alternativas que podem ser utilizadas são as proteções do cultivar por sombrite e plásticos de estufas ou outra opção mais elaborada para a produção de vegetais é a escolha pelos tipos mais rústicos. No entanto, algumas espécies podem ser semeadas em épocas mais quentes, desde que seja cultivares adaptadas, são essas denominadas cultivares de verão como é o caso da alface, repolho, couve-flor e cenoura (Sediyama et al. 2020). Segundo o IBGE (2017), a produção agrícola dos municípios paraenses obteve um aumento de 170\% entre os anos de 2006 a 2013. Esse levantamento registrou que os produtos das plantações alcançaram cerca de $\mathrm{R}$ \$ 5,4 bilhões em 2013, somando aproximadamente $\mathrm{R} \$ 3,4$ bilhões a mais que em 2006.

Desta maneira o objetivo deste estudo foi avaliar o perfil socioeconômico dos sistemas de produção e aquisição de hortaliças pela população do município de Xinguara-PA durante a pandemia da COVID-19.

\section{Metodologia}

A primeira etapa da pesquisa foi realizada entre agosto de 2020 a março de 2021 nos municípios de Xinguara e Rio Maria do estado do Pará. Em decorrência da pandemia da COVID-19, a coleta dos dados foi realizada por meio de um questionário semi-estruturado aplicado via aplicativo eletrônico de mensagens Whatsapp e Google formulário, composto por 36 perguntas de rápidas respostas com o objetivo de traçar o perfil de produção de hortaliças e o padrão socioeconômico dos horticultores da região.

No questionário para verificação dos sistemas de cultivo de hortaliças, aplicados aos produtores rurais abordaram duas vertentes:

a) características gerais de produção e comercialização como a tamanho da área destinada para a horticultura, tempo de atuação na área da agricultura, sistema de abastecimento e de cultivo na propriedade, presença ou ausência de assistência técnica durante o processo produtivo, variedades de vegetais produzidos e volume mensal de produção, tipo de mão de obra utilizada na propriedade entre outros; 
b) características do perfil socioeconômico dos produtores como gênero, idade, grau de escolaridade, quantidade de pessoas na família que atuam no processo de produção, principal atividade de renda na propriedade e a renda oriunda da horticultura, importância da produção de vegetais para o incremento da renda familiar, forma de comercialização das hortaliças entre outros;

$\mathrm{Na}$ segunda etapa da pesquisa, além dos horticultores os moradores do município da cidade de Xinguara-PA foram convidados para participarem da entrevista relacionada a aquisição de hortaliças. A coleta dos dados foi realizada por meio de um questionário semiestruturado, com 26 perguntas de rápidas respostas com o objetivo de traçar o perfil de consumo dos consumidores de hortaliças da cidade de Xinguara do Pará.

No questionário para verificação das formas de aquisição e preferência de consumo de hortaliças, foi abordado os seguintes aspectos:

a) as características gerais do hábito de consumo, tipos de vegetais preferidos e frequência de consumo de verduras e legumes, locais de compra das hortaliças, dias da semana para realização das compras entre outros;

b) características dos consumidores e do perfil socioeconômico como gênero, idade, grau de escolaridade, estado civil, cidade de origem, renda mensal da família, gasto semanal com a compra de verduras e legumes entre outros;

O projeto foi submetido e aprovado pelo Comitê de Ética em Pesquisa Humana da Universidade Federal do Pará número CAAE 32872120.1.0000.0018 e as pessoas que aceitaram participar do estudo assinaram um Termo de Consentimento Livre e Esclarecido (TCLE).

\section{Resultados e Discussão}

\subsection{Produção de hortaliças}

Dentre os produtores entrevistados, o tempo de atuação no cultivo de hortaliças dos municípios da microrregião estudada foi diversificado. Foram entrevistados 10 produtores de hortaliças dos municípios de Xinguara e Rio Maria, sendo 30\% do gênero feminino e $70 \%$ do masculino, $10 \%$ com idades entre 18 e 30 anos, $30 \%$ entre 31 e 40 anos, $30 \%$ e 40 anos e $30 \%$ acima de 51 anos. Do total de horticultores, $40 \%$ possuem o ensino fundamental incompleto, $10 \%$ ensino médio incompleto, $30 \%$ ensino médio completo e $20 \%$ sendo analfabeto. Ao avaliarmos o estado civil, foi verificado que $40 \%$ dos produtores são casados, $20 \%$ solteiros, $10 \%$ viúvos e $10 \%$ optaram por não responder.

Dos entrevistados, $40 \%$ são oriundos do estado do Pará, 40\% do estado do Maranhão, 10\% do estado da Bahia e 10\% não responderam, sendo que $80 \%$ atualmente residem no município de Xinguara e 20\% em Rio Maria, ambos localizados na região sudeste do estado do Pará. Nota-se que a partir do crescimento e melhoramento das rodovias do estado do Pará houve um aumento considerável na população migrante, o que possibilitou a incorporação de novas áreas ao processo produtivo dos produtores rurais.

Dentre os entrevistados, $60 \%$ atuam na agricultura a mais de seis anos, $10 \%$ atuam entre três e seis anos e 30\% atuam menos de três anos, sendo que $70 \%$ possuem sua produção na zona urbana e 30\% na zona rural. Quanto ao tempo de trabalho na produção de vegetais, $50 \%$ dos produtores dedicam entre cinco e oito horas/dia, 20\% entre nove e 12 horas/dia e 30\% dos entrevistados acima de 12 horas/dia (Tabela 1). Assim como no estudo realizado por Leite \& Lopes (2012) foi possível observar o crescimento das atividades agrícolas em espaços urbanos, como estratégia para o abastecimento alimentar das cidades e flexibilizar o desenvolvimento socioeconômico dos produtores. Essa prática em torno das cidades está relacionada diretamente ao abastecimento dos hortifrutigranjeiros, supermercados e até mesmo nas feiras-livre. 
Tabela 1 - Dados de idade, estado civil, perímetro residencial, grau de escolaridade, tempo de atuação na agricultura e horas por dia dedicadas a produção de vegetais dos produtores entrevistados $(n=10)$ nos municípios de Xinguara e Rio Maria do estado do Pará.

\begin{tabular}{|c|c|c|}
\hline \multirow{4}{*}{ Idade dos entrevistados } & Entre 18 e 30 anos & $10 \%$ \\
\hline & Entre 31 e 40 anos & $30 \%$ \\
\hline & Entre 41 e 50 anos & $30 \%$ \\
\hline & Acima de 51 anos & $30 \%$ \\
\hline \multirow{4}{*}{ Estado civil } & Casado (a) & $40 \%$ \\
\hline & Solteiro (a) & $40 \%$ \\
\hline & Viúvo(a) & $10 \%$ \\
\hline & Não responderam & $10 \%$ \\
\hline \multirow{2}{*}{ Perímetro residencial } & Zona urbana & $70 \%$ \\
\hline & Zona rural & $30 \%$ \\
\hline \multirow{5}{*}{ Grau de escolaridade } & Ensino fundamental incompleto & $40 \%$ \\
\hline & Ensino fundamental completo & $0 \%$ \\
\hline & Ensino médio incompleto & $10 \%$ \\
\hline & Ensino médio completo & $30 \%$ \\
\hline & Analfabeto & $20 \%$ \\
\hline \multirow{3}{*}{ Tempo de atuação na agricultura } & Entre um a três anos & $30 \%$ \\
\hline & Entre três a seis anos & $10 \%$ \\
\hline & Acima de seis anos & $60 \%$ \\
\hline \multirow{3}{*}{ Horas/dia dedicadas a produção de vegetais } & Entre cinco e oito & $50 \%$ \\
\hline & Entre nove e 12 & $20 \%$ \\
\hline & Acima de 12 & $30 \%$ \\
\hline
\end{tabular}

Fonte: Autores.

Em 40\% das propriedades, a principal atividade de renda são as hortaliças (legumes e verduras), 40\% somente verduras folhosas e $20 \%$ verduras, legumes e animais de produção como principais atividades de renda (Figura 1A). Dos tipos de vegetais produzidas nas propriedades, $40 \%$ produzem verduras folhosas como alface, agrião, cebolinha, coentro, couve, rúcula, salsa, $40 \%$ produzem verduras, legumes e leguminosas como alface, rúcula, coentro, cebolinha, pepino, quiabo, abobrinha, tomate cereja, pimenta de cheiro, couve, maxixe, jiló, cebola, rabanete, mandioca e mostarda e $20 \%$ produzem verduras, leguminosas e frutas alface, coentro, cebolinha, limão, quiabo, jiló, maxixe, cheiro verde, couve limão, maracujá, abóbora, limão taiti e laranja (Figura 1B). Entretanto, o que se observa é a escassez de diversidade de produtos tanto de vegetais como a chicória, almeirão, acelga, espinafre e agrião e dos legumes e tubérculos como a ervilha, mandioquinha, abóbora cabotia entre outros. A pouca diversidade de vegetais é tanto devida a baixa procura dos consumidores por esses tipos de produtos na região como a ausência de informações dos produtores de como se realiza o plantio. Em entrevista a um produtor de verduras, quando questionado do porquê de não produzir determinado tipo de verdura ele relatou que tentou outras vezes o plantio de espinafre, porém não sabia o tempo de corte do produto, com isso, acabou desistindo do cultivo desse vegetal.

Em relação a porção de verduras folhosas produzidas mensalmente, $10 \%$ dos produtores afirmam produzir 400 pacotes, $30 \%$ entre mil a dois mil pacotes, $10 \%$ acima de dois mil pacotes e 50\% afirmam não saber do volume produzido (Figura 1C). 
A ausência do controle de produção também foi verificada na produção de legumes, pois os agricultores que produzem não souberam responder sobre o volume real produzido.

Dos vegetais (frutas, verduras e legumes) produzidos, 30\% comercializam somente para os supermercados dos municípios da região, $40 \%$ na feira-livre local, $10 \%$ tanto nos supermercados como na propriedade agrícola, $10 \%$ na feira-livre e nos supermercados e 10\% somente na própria horta (Figura 1D). A maior frequência de comercialização dos produtos ocorre nas feiras-livres, esse espaço ocorre pela facilidade de venda e, principalmente, pelo contato direto com o consumidor, que facilita a possível alteração dos valores pelo ato da famosa "pechincha" e diferente do que ocorre nos supermercados que possuem seus valores fixos dos produtos, além da exposição das verduras em local aberto e essa observação também foi relatada por Sá et al., (2006) nos municípios de Santarém e Belém-PA.

Figura 1 - Dados de produção: A) principal atividade de renda da propriedade; B) variedades de verduras produzidas; C) volume mensal de verduras folhosas produzidas; D) locais de venda dos vegetais produzidos.

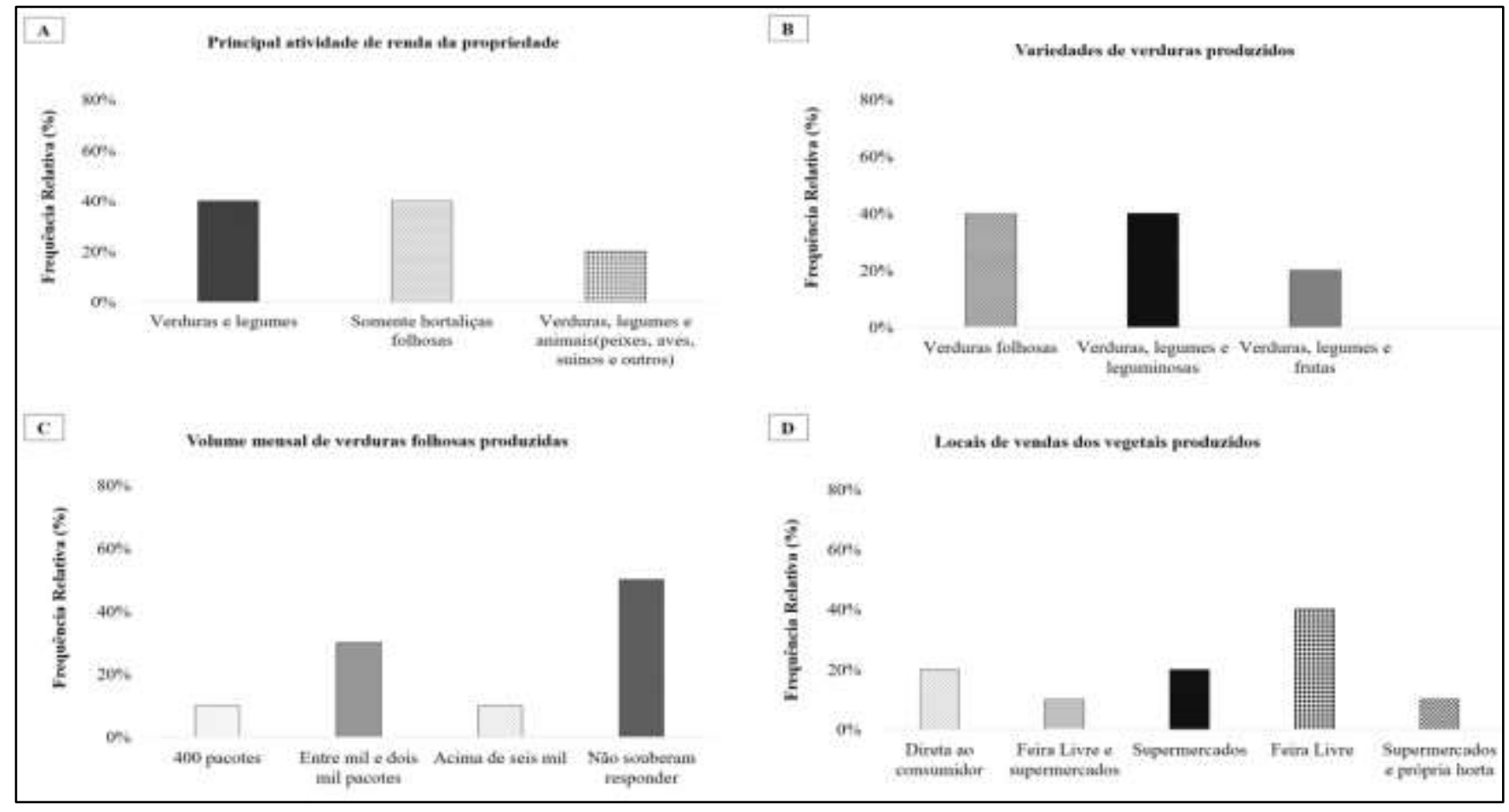

Fonte: Autores.

Quando questionados em relação a área da propriedade direcionada a produção de vegetais, $80 \%$ destinam menos de um hectare e $20 \%$ entre um a cinco hectares. A área destinada a produção das verduras folhosas, $50 \%$ utilizam menos que $10 \%$ da propriedade, $20 \%$ utilizam entre $11 \%$ a $50 \%$ da propriedade, $10 \%$ entre $51 \%$ a $70 \%$ da propriedade, $10 \%$ entre $71 \%$ a $90 \%$ e $10 \%$ acima de $91 \%$ da propriedade. A área destinada a produção de legumes da área total da propriedade agrícola, 30\% dos produtores utilizam menos que $10 \%$ da propriedade, $30 \%$ utilizam entre $11 \%$ e 50\% da propriedade e $40 \%$ não possuem área destinada para a produção de vegetais (Tabela 2). É importante destacar que o tamanho da área destinada para o cultivo encontrase associado a capacidade produtiva da família, assim como destacou Castro et al. (2015), neste trabalho, acima de70\% dos entrevistados utilizam em suas propriedades mão de obra familiar.

Em relação ao sistema de cultivo utilizado nas propriedades, $80 \%$ sistema semi-intensivo (média produção para consumo da família e venda) e $20 \%$ produzem em sistema intensivo de produção (alta produção com objetivo de comercialização). Quanto ao tipo de agricultura utilizada nas propriedades, $80 \%$ utilizam o sistema de agricultura convencional, 
20\% produzem em sistema orgânico e $40 \%$ utilizam sistema comercial (Tabela 2). Observa-se a preocupação dos produtores em fornecer um produto de qualidade ao consumidor e quando questionados sobre o uso de produtos químicos, relataram que utilizam em pequenas quantidades somente para o controle de pragas, como também foi observado no estudo de Honda et al., (2016) avaliando a produção de legumes.

Tabela 2 - Dados referentes a área destinada a produção de vegetais, área destinada a produção de verduras folhosas, área destinada a produção de legumes, sistema de cultivo utilizado e tipo de agricultura utilizada nas propriedades dos municípios de Xinguara e Rio Maria do estado do Pará.

\begin{tabular}{|c|c|c|}
\hline \multirow[t]{3}{*}{ Área destinada a produção de vegetais } & Menos de um hectare & $80 \%$ \\
\hline & Entre um a cinco hectares & $20 \%$ \\
\hline & $\begin{array}{l}\text { Menor que } 10 \% \text { da propriedade para produção de } \\
\text { hortaliças }\end{array}$ & $50 \%$ \\
\hline \multirow[t]{5}{*}{$\begin{array}{l}\text { Área destinada a produção de verduras } \\
\text { folhosas }\end{array}$} & Entre $11 \%$ a $50 \%$ da propriedade & $20 \%$ \\
\hline & Entre $51 \%$ a $70 \%$ & $10 \%$ \\
\hline & Entre $71 \%$ a $90 \%$ & $10 \%$ \\
\hline & Acima de $91 \%$ da propriedade & $10 \%$ \\
\hline & Menor que $10 \%$ da propriedade & $30 \%$ \\
\hline \multirow[t]{2}{*}{ Área destinada a produção de legumes } & Entre $11 \%$ a $50 \%$ da propriedade & $30 \%$ \\
\hline & Não possui & $40 \%$ \\
\hline \multirow[t]{3}{*}{ Sistema de cultivo utilizado } & $\begin{array}{l}\text { Sistema semi-intensivo (média produção para } \\
\text { consumo da família e venda) }\end{array}$ & $80 \%$ \\
\hline & $\begin{array}{l}\text { Sistema intensivo de produção (alta produção com } \\
\text { objetivo de comercialização) }\end{array}$ & $20 \%$ \\
\hline & Agricultura convencional & $80 \%$ \\
\hline Tipo de agricultura utilizada & Agricultura orgânica (sem agrotóxico) & $20 \%$ \\
\hline
\end{tabular}

Fonte: Autores.

Dentre os entrevistados, $40 \%$ possui produção de hortaliças como um complemento da renda familiar e $60 \%$ como única fonte de renda. Dos produtores que possuem a produção de hortaliças como única fonte de renda, $30 \%$ recebe menos que um salário mínimo, $50 \%$ entre um e dois e $20 \%$ entre dois e quatro salários mínimos (Figura 2A), a renda dos produtores divide-se entre o sustento da família e a manutenção das hortaliças. Couto et al. (2017), destacaram que para os produtores de hortaliças da região de São Jorge e São José, Região Cacaueira, no estado da Bahia, vários fatores influenciam na busca desse complemento de renda, tais como escolaridade, idade, tamanho das famílias e o tamanho da área usada na produção.

Em relação aos efeitos da pandemia da Covid-19 na produção e vendas, $70 \%$ dos entrevistados afirmaram que foram afetados de forma razoável, $20 \%$ definiram como péssimos os efeitos da pandemia na produção e comercialização e $10 \%$ afirmaram que não houve interferências na produção e ou comercialização (Figura 2B). Dentre os produtores que relataram impacto na produção e comercialização, $10 \%$ afirmaram queda nas vendas entre $51 \%$ a $70 \%$, $90 \%$ relataram diminuição de até 
10\% nas vendas (Figura 2C). Com o início da pandemia da Covid-19 houve a suspensão de algumas práticas como, por exemplo, a venda das hortaliças nas feiras-livres e nos supermercados, o que acarretou um impacto significativo na produção familiar, pois a produção é prejudicada com a falta dos protocolos de segurança sanitária, assim como o estudo publicado por Salazar et al. (2020), que avaliou os efeitos da pandemia na produção familiar.

Figura 2 - Dados dos produtores entrevistados nos municípios de Xinguara e Rio Maria no estado do Pará sobre: A) porcentagem da renda familiar oriunda da agricultura; B) impacto causado pela Covid-19 na produção de vegetais; C) diminuição na comercialização dos vegetais produzidos.

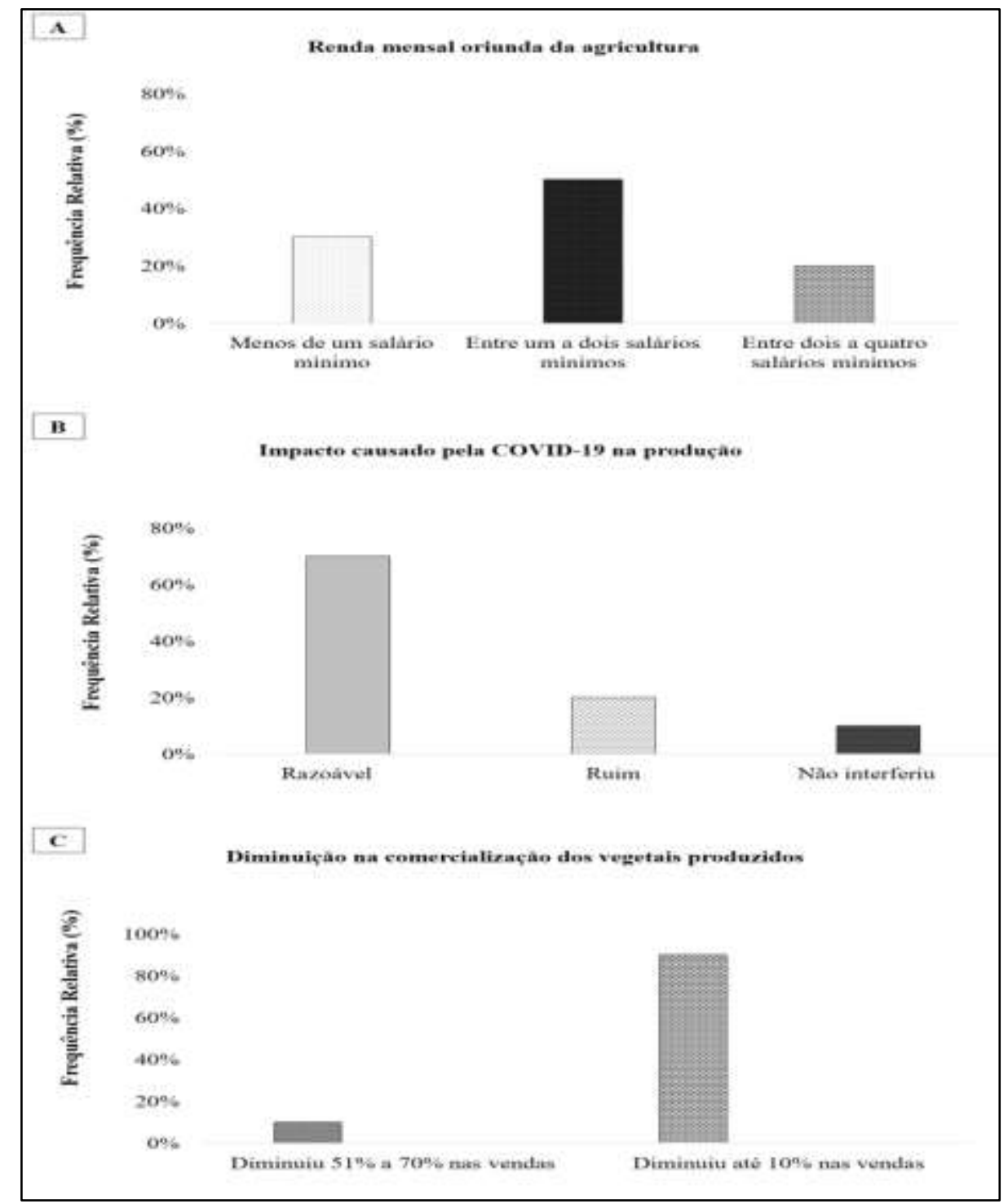

Fonte: Autores.

Dos entrevistados, $70 \%$ produzem em sistema de produção comum e 30\% possuem sistema de produção em sistema de hidroponia. Dos produtores que utilizam a produção em sistema hidropônico, 66,67\% atuam com esse sistema entre um e dois anos e 33,33\% acima de cinco anos. Entre os entrevistados, somente 10\% utilizam sistema de produção em estufas com utilização de menos de um hectare da propriedade e $40 \%$ produzem em sistema orgânico. Além disso, $70 \%$ das propriedades utilizam água de poço para abastecimento da propriedade, $20 \%$ utilizam água de rios ou lagos e $10 \%$ fazem uso de água encanada (Tabela 3). 
Comparando o sistema de produção convencional e o sistema orgânico, ambos possuem uma pequena diferença no custo de produção. A produção orgânica requer menor gasto com insumos e mão de obra, quando se comparado a produção em sistema convencional que utiliza maiores insumos como os defensivos agrícolas. Entretanto, o preço final do produto no sistema convencional é mais acessível a população, pois no sistema orgânico a oferta de produtos é menor que a demanda, com isso, os produtores conseguem agregar valor a mercadoria. Outro fator observado nesse estudo é que apesar da pouca demanda por produtos orgânicos, a receita liquida de algumas hortaliças orgânicas acabam sendo superiores à receita das mesmas hortaliças cultivadas em sistema convencional. (Souza \& Garcia 2013).

A produção de vegetais em sistema hidropônico vem sendo uma alternativa de produção em ambientes pequenos, com pouca utilização de água e reciclagem de nutrientes, porém, mesmo sendo uma ótima escolha para otimizar espaço e maximizar a produção, a falta de conhecimentos técnicos básicos dos produtores rurais faz com que essa técnica se delimite apenas em algumas propriedades. Apesar de haver uma preocupação referente ao acúmulo de nitrato no sistema de hidroponia, os alimentos produzidos nesse sistema são altamente saudáveis, uma vez que o teor de nitrato se encontra abaixo dos níveis consideráveis críticos (Ohse et al. 2012).

Tabela 3 - Dados referentes a utilização de sistema de hidroponia, tempo de utilização do sistema hidropônico, uso de sistema em estufas, área destinada a produção de vegetais em estufas, produção orgânica e tipo de abastecimento de água usado nas propriedades rurais dos municípios de Xinguara e Rio Maria do estado do Pará.

\begin{tabular}{llc}
\hline Utiliza sistema de hidroponia & Sim & $30 \%$ \\
& Não & $70 \%$ \\
$\begin{array}{l}\text { Quanto tempo utiliza o sistema } \\
\text { hidropônico }\end{array}$ & Entre um a dois anos & $66,67 \%$ \\
& Acima de cinco anos & $33,33 \%$ \\
$\begin{array}{l}\text { Utiliza sistema de produção em } \\
\text { estufas }\end{array}$ & Sim & $10 \%$ \\
& Não & $90 \%$ \\
$\begin{array}{l}\text { Área utilizada para a produção } \\
\text { de vegetais em estufas }\end{array}$ & Menos que um hectare & $10 \%$ \\
& Não possui & $90 \%$ \\
Produção orgânica de vegetais & Sim & $40 \%$ \\
& Não & $60 \%$ \\
Tipo de abastecimento de água & Água de rio ou lago & $20 \%$ \\
& Água de poço & $70 \%$ \\
& Água encanada & $10 \%$ \\
\hline
\end{tabular}

Fonte: Autores.

Dos entrevistados, $70 \%$ utilizam somente mão de obra familiar na propriedade e 30\% utilizam familiar e contratada. Quando perguntado sobre a quantidade de pessoas da família que atuam na produção de vegetais, $40 \%$ afirmam que apenas uma pessoa atua na produção, $50 \%$ entre duas e três pessoas e $10 \%$ entre três e quatro pessoas. Em relação as pessoas que residem na mesma residência, $20 \%$ afirmam que entre uma e duas pessoas residem na mesma residência, $60 \%$ entre três e quatro pessoas 10\% entre cinco a seis pessoas e 10\% acima de seis pessoas residem na mesma residência (Tabela 4). Neste trabalho, as famílias são geralmente formadas por mais de 4 membros, possuem ajuda dos filhos na produção como complemento da mão de obra, o que contribui na diminuição com mão de obra contratada. Segundo Freitas et al. (2017), o trabalho familiar na produção isenta 
os produtores que não possuem vínculos trabalhistas de taxas de impostos, pois as famílias formadas com dois a quatro membros possuem uma maior lucratividade com predominância na produção de hortaliças.

Tabela 4 - Dados referentes a mão de obra utilizada nas propriedades, pessoas da família que atuam na produção dos vegetais, pessoas que residem na mesma residência nos municípios de Xinguara e Rio Maria do estado do Pará.

\begin{tabular}{llc}
\hline $\begin{array}{l}\text { Mão de obra utilizada na } \\
\text { propriedade }\end{array}$ & Somente familiar & $70 \%$ \\
& Familiar e contratada & $30 \%$ \\
& Apenas uma pessoa & $40 \%$ \\
$\begin{array}{l}\text { Pessoas da família atuam na } \\
\text { produção dos vegetais }\end{array}$ & Entre duas a três pessoas & $50 \%$ \\
& Entre três a quatro pessoas & $10 \%$ \\
$\begin{array}{l}\text { Pessoas que residem na mesma } \\
\text { residência }\end{array}$ & Entre uma e dois pessoas & $20 \%$ \\
& Entre três e quatro pessoas & $60 \%$ \\
& Entre cinco a seis pessoas & $10 \%$ \\
& Acima de seis pessoas & $10 \%$ \\
\hline
\end{tabular}

Fonte: Autores.

Referente a quantidade de cômodos nas residências, $20 \%$ possuem três cômodos, $10 \%$ quatro cômodos, $50 \%$ cinco cômodos e $10 \%$ não responderam. Quando perguntados se havia aposentados na família, 20\% disseram que há aposentados na família e $80 \%$ não possem aposentados na família. Os produtores, solicitam assistência técnica, mas afirmam não receber nas propriedades, o que afeta na qualidade da produção. Do total dos entrevistados $90 \%$ afirmam estar feliz com a atividade agrícola e $10 \%$ dizem que não.

\subsection{Consumo de Vegetais}

Foram entrevistadas cerca de 150 pessoas apresentando idade entre 15 e 74 anos, sendo a maior parte $70,7 \%$ jovens adultos entre 15 e 30 anos e do número total de pessoas entrevistadas $58 \%$ foram do gênero feminino e $42 \%$ do masculino.

Do total de entrevistados 5,7\% possuem fundamental incompleto, 2,8\% ensino fundamental completo, $24,3 \%$ ensino médio incompleto, 39,3\% ensino médio completo, 15\% ensino superior ou técnico incompleto e 12,9\% apresentam ensino superior completo. Em relação ao estado civil dos entrevistados, 21,6\% declararam ser casados, $72,3 \%$ solteiros, $4,1 \%$ divorciados e $2 \%$ viúvos (Tabela 5 ).

Quando questionados em relação a cidade natal, 73,5\% relataram ter nasci do no estado do Pará, 8,7\% no estado de Goiás, 5,6\% no estado do Maranhão, 5,6\% no estado do Tocantins, 3,4\% no estado do Ceará, 0,7\% no estado de Minas Gerais, 1,4\% no estado do Piauí e 2\% no estado da Bahia. Atualmente, $96 \%$ dos entrevistados residem no estado do Pará, 2,7\% no estado de Goiás e 1,3\% no estado da Bahia. Do total de entrevistados, 89,1\% dos consumidores de hortaliças possuem sua residência localizada na zona urbana e $10,9 \%$ na zona rural (Tabela 5). 
Tabela 5 - Idade, grau de escolaridade, estado civil, cidade de origem, cidade atual e localização da residência dos consumidores de hortaliças $(\mathrm{n}=150)$ do município de Xinguara do estado do Pará.

\begin{tabular}{|c|c|c|}
\hline \multirow[t]{5}{*}{ Idade dos entrevistados } & Entre 15 e 30 anos & $70,7 \%$ \\
\hline & Entre 31 e 40 anos & $15,3 \%$ \\
\hline & Entre 41 e 50 anos & $7,3 \%$ \\
\hline & Entre 51 e 60 anos & $4,7 \%$ \\
\hline & Acima de 61 anos & $2 \%$ \\
\hline \multirow[t]{7}{*}{ Grau de escolaridade } & Ensino fundamental incompleto & $6,2 \%$ \\
\hline & Ensino fundamental completo & $3,4 \%$ \\
\hline & Ensino médio incompleto & $23,3 \%$ \\
\hline & Ensino médio completo & $38,4 \%$ \\
\hline & Ensino superior/técnico incompleto & $14,4 \%$ \\
\hline & Ensino superior/técnico completo & $14,4 \%$ \\
\hline & Analfabeto & $0 \%$ \\
\hline \multirow[t]{4}{*}{ Estado civil } & Casado(a) & $21,6 \%$ \\
\hline & Solteiro(a) & $72,3 \%$ \\
\hline & Divorciado(a) & $4,1 \%$ \\
\hline & Viúvo(a) & $2 \%$ \\
\hline \multirow[t]{8}{*}{ Qual estado de origem (nascimento) } & Pará & $73,5 \%$ \\
\hline & Goiás & 8,7 \\
\hline & Maranhão & $5,6 \%$ \\
\hline & Tocantins & $5,6 \%$ \\
\hline & Ceará & $3,4 \%$ \\
\hline & Minas Gerais & $0,7 \%$ \\
\hline & Piauí & $1,4 \%$ \\
\hline & Bahia & $2,0 \%$ \\
\hline \multirow[t]{3}{*}{ Qual estado reside atualmente } & Pará & $96 \%$ \\
\hline & Goiás & $2,7 \%$ \\
\hline & Ceará & $1,3 \%$ \\
\hline \multirow[t]{2}{*}{ Sua residência se localiza na } & Zona urbana & $89,1 \%$ \\
\hline & Zona Rural & $10,9 \%$ \\
\hline
\end{tabular}

Fonte: Autores.

Quando questionados em relação a frequência de compra dos vegetais, a maioria 68,1\% afirmou que realiza a compra somente uma vez na semana, $16 \%$ três vezes na semana, $14,6 \%$ acima de três vezes na semana e uma pequena parcela de pessoas não realizam compra dos vegetais. A baixa frequência de compra de hortaliças possui relação com a rotina de trabalho das pessoas entrevistadas, sendo essas compras realizadas, na maioria das vezes, em dias de folgas ou tempo livre nos finais de 
semana. Em relação aos dias da semana em que as compras são realizadas, observou-se que as pessoas realizam as compras com mais frequência nas quartas-feiras e nos finais de semana sábados e, isso está associado aos dias de promoções e reposição de mercadorias nos supermercados como também ao maior fluxo de vendas na feira-livre do município aos fins de semana (Tabela 6). Moreira et al. (2012) verificou resultado semelhante no munícipio de bom Jesus-PI, onde as pessoas participantes do estudo declararam realizar as compras de hortaliças no dia de sábado, os locais preferidos para compra são feiras-livres e supermercados, sendo na feira-livre destacado pela qualidade e variedade de produtos encontrados.

Tabela 6 - Frequência e dias da semana que são realizadas as compras dos vegetais pelos consumidores de hortaliças ( $\mathrm{n}=150$ ) do município de Xinguara do estado do Pará.

\begin{tabular}{llr}
\hline Frequência de compra dos & Uma vez na semana & $67,3 \%$ \\
vegetais (legumes e verduras)? & Três vezes na semana & $16,7 \%$ \\
& Acima de três vezes na semana & $14 \%$ \\
& Não compra vegetais & $2 \%$ \\
Dias da semana que realiza a & & \\
compra dos vegetais? & Segunda-feira & $10,7 \%$ \\
& Terça-feira & $4,7 \%$ \\
& Quarta-feira & $28,9 \%$ \\
& Quinta-feira & $2,7 \%$ \\
& Sexta-feira & $10,1 \%$ \\
& Sábado e Domingo & $42,9 \%$ \\
\hline
\end{tabular}

Fonte: Autores.

A maior parte das pessoas entrevistadas afirmaram consumir frequentemente pelo menos quatro tipo de vegetais folhosos e um tipo de legume ou fruto. O resultado da avaliação geral pela preferência de consumo de verduras folhosas apontou que entre as preferidas estão alface, couve, coentro e cebolinha representando $60,4 \%$ da frequência e o fruto mais consumido é o tomate. Uma pequena parcela dos entrevistados 10,7\% disseram não consumir nenhum tipo de verduras ou legumes (Figura 3). Nos trabalhos de Viana et al. (2020) e Moreira et al. (2012) constaram que entre as hortaliças folhosas que apresentam maior preferência por parte dos consumidores é a alface e entre os temperos o coentro e cebolinha, evidenciando assim que a alface possui preferência de consumo em outras regiões. Já no trabalho de Souza et al. (2016), em relação a ingestão diária de legumes, temperos e frutas entre os jovens do estado do Maranhão, apresentam destaque a cebola, cheiro verde e tomate.

Nesse estudo avaliando o consumo de hortaliça no município de Xinguara-PA foi observado que 20,8\% consomem verduras somente uma vez na semana, 31,3\% consomem verduras duas a três vezes na semana, 31,9\% consomem acima de três vezes na semana, 11,8\% consomem verduras diariamente e 4,2\% não consomem verduras. Em relação aos tipos de legumes ou fruto consumido com maior frequência, o tomate representa $92,3 \%$, sendo esse um número significativo, isso se dá devido à grande disponibilidade do fruto em supermercados e feira-livre da cidade, pois a maior parte das pessoas entrevistadas realizam a aquisição dos vegetais nesses locais (Figura 3). Segundo Viana et al. (2020), a população de São Luís do Maranhão possui preferência em adquirir hortaliças folhosas comercializadas nas feiras-livres da cidade, com frequência de ingestão diária e semanal desses vegetais. Resultados similares foi identificado no estudo no município de Iguatu-CE, onde a maior parte dos consumidores de hortaliças consomem mais o cheiro verde, tomate e a alface (Francilino et al. 2014). 
Figura 3 - Dados dos consumidores de hortaliças do município de Xinguara do estado do Pará A) Folhosas consumidas com maior frequência; B) Consumo semanal de verdura; C) Legumes e frutos consumidos com maior frequência; C) Consumo semanal de legumes.

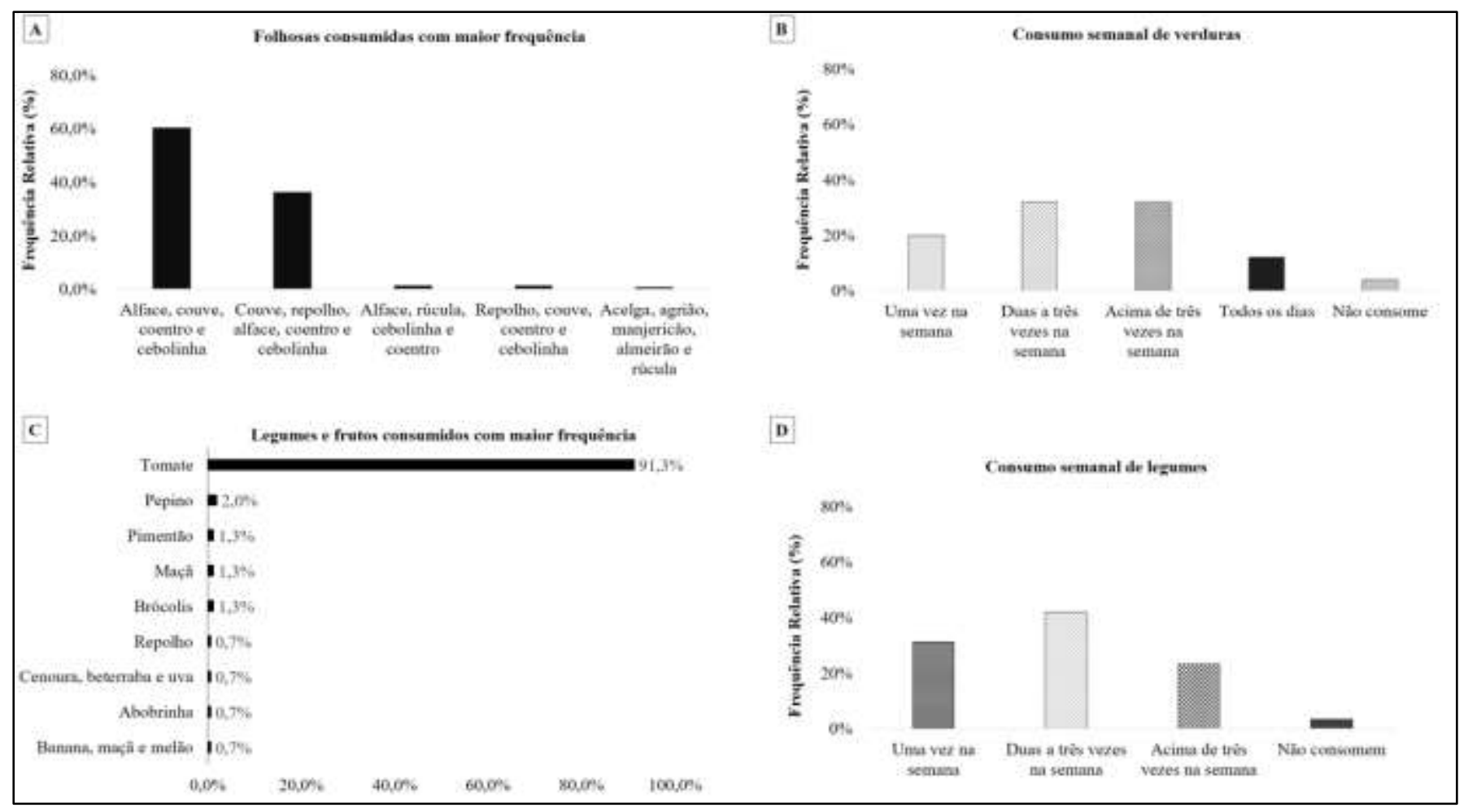

Fonte: Autores.

Conforme as respostas das pessoas que participaram das entrevistas, os principais locais que realizam as compras dos vegetais são supermercados com 74,3\%, seguido por feira-livre 20,8\%, e os demais 4,9\% das pessoas restantes realizam as compras dos vegetais em hortifrutis, sacolão ou alternam as compras entre feiras-livres e supermercados. Essa preferência por local, pode ser explicada devido a variedade de vegetais e demais produtos alimentícios que podem ser encontrados no local, tornando mais rápido e prático realização das compras dos alimentos e utensílios domésticos (Figura 4).

Amor et al. (2012) em seu estudo realizado na cidade de Santo Antônio de Jesus-BA, verificou que a população local possui maior preferência em adquirir hortaliças nas feiras-livres, devido à proximidade do trabalho e o frescor dos vegetais encontrados. Já Souza et al. (2008) identificaram que na região central do Rio Grande do Sul um perfil diferenciado de consumidores, que possuem preferência em realizar a compra das hortaliças nos supermercados ou hipermercados.

Na feira municipal da cidade de Xinguara no estado do Pará, realizada aos fins de semana e em algumas datas comemorativas, em conversa com os vendedores de verduras, foi observado que os consumidores apresentam preferência por folhosas, como alface, couve e cheiro verde sendo que ambos são comercializados por preço médio de R $\$ 5,00$. Já o fruto mais comercializado é o tomate, vendido com preço médio de $\mathrm{R} \$ 4,50$ o quilo. A escolha por esses determinados vegetais está relacionada a praticidade da utilização em saladas como também a utilização como tempero (Figura 4). No estudo de Tofanelli et al. (2007), na busca da caracterização dos principais produtos hortícolas comercializados no município de Mineiros-GO, observou-se que além do tomate, a melancia, a cebola e a batata inglesa apresentaram maior consumo pela população entrevistada. 
Figura 4 - Dados dos consumidores de hortaliças do município de Xinguara do estado do Pará. A) Local de compra dos vegetais dos consumidores de hortaliças do município de Xinguara do estado do Pará; B) Horário de compra dos vegetais dos consumidores de hortaliças do município de Xinguara do estado do Pará.



Fonte: Autores.

$\mathrm{Na}$ avaliação da higiene do local de compra, 14,7\% dos entrevistados definiram como ótima, 55,2\% afirmaram ser boa, 28,7\% disseram ser razoável e 1,4\% declararam ser péssima. Além da higiene do local foi avaliado também a qualidade das hortaliças, onde $23,8 \%$ dos participantes das entrevistas disseram ser de ótima qualidade, 43,4\% de boa qualidade, 30,8\% razoável e 2,0\% péssima (Tabela 7). A classificação do local de compra neste trabalho foi melhor do que a obtida no estudo realizado por Alves et al. (2014), onde os consumidores de produtos do hortifruti do complexo Ver-o-Peso do município de Belém-PA definiram em sua maioria a higiene do local como razoável ou ruim.

Outro ponto relevante abordado é em relação ao gasto médio com verduras por compra, onde 8,3\% gastam menos de $\mathrm{R} \$ 10,00$ reais por compra, 27,8\% entre $\mathrm{R} \$ 11,00$ e $\mathrm{R} \$ 20,00$ reais, 27,8\% entre $\mathrm{R} \$ 21,00$ e $\mathrm{R} \$ 30,00$ reais, $16,7 \%$ entre $\mathrm{R} \$ 31,00$ e $\mathrm{R} \$ 40,00$ reais e 19,4\% gastam acima de 40 reais. O gasto médio por compra está relacionado com a parcela de pessoas na família e ao hábito de consumo de hortaliças dos entrevistados e familiares. Já em relação ao gasto médio semanal com compra de legumes, $12,6 \%$ possui gasto menor que $\mathrm{R} \$ 10,00$ reais, 40,6\% gastam entre $\mathrm{R} \$ 11,00$ e $\mathrm{R} \$ 30,00$ reais, 29,4\% entre $\mathrm{R} \$ 31,00$ e $\mathrm{R} \$ 50,00$ reais, 7,7\% entre $\mathrm{R} \$ 51,00$ e $\mathrm{R} \$ 60,00$ reais, 6,3\% entre $\mathrm{R} \$ 61,00$ e $\mathrm{R} \$ 70,00$ reais e os demais 3,4\% gastam acima de $\mathrm{R} \$ 70,00$ reais na compra semanal de legumes (Tabela 7). Guerra et al. (2018), verificaram que a maior parte dos consumidores de hortaliças no município de Barra- BA, gastam menos de $\mathrm{R} \$ 50,00$ reais por compra dos vegetais. Já na feira livre de Bom Jesus-PI, Moreira et al. (2012) identificou que o gasto da maior parte os consumidores por compra são entre $\mathrm{R} \$ 10,00$ a $\mathrm{R} \$ 20,00$ reais, sendo resultados semelhantes aos valores encontrados neste trabalho.

Quando questionados sobre os fatores que influenciam na decisão de compra de hortaliças, 68,3\% analisam o preço é a qualidade, 14, $1 \%$ buscam saber a origem do produto e o preço, 10,6\% a qualidade das hortaliças e a facilidade de aquisição, $5,6 \%$ o preço e a facilidade e 1,4\% escolhem devido a poucas opções ou pelo benefício a saúde. O horário de compra preferido dos entrevistados é a parte da manhã (Tabela 7). Neta et al. (2013), constataram que no município de Apodi-RN, a população local possui como principais critérios no momento de aquisição das hortaliças, o ponto de vista nutricional, o preço e a aparência dos produtos, sendo destacado o fato que hortaliças possuem características saudáveis. 
Tabela 7- Avaliação da qualidade das hortaliças, higiene do local de compra, fatores que influenciam na decisão de compra das hortaliças, gasto médio com verdura por compra e gasto semanal na compra de legumes por parte dos consumidores de hortaliças ( $n=150)$ da cidade de Xinguara do estado do Pará e região.

\begin{tabular}{llr}
\hline Como define a qualidade das hortaliças & Ótima & $23,5 \%$ \\
encontradas em seu município & Boa & $44,3 \%$ \\
& Razoável & $30,2 \%$ \\
& Ruim & $1,3 \%$ \\
$0,7 \%$
\end{tabular}

$\begin{array}{llr}\text { Quanto a higiene do local de compra, como você } & \text { Ótima } & 14,1 \% \\ \text { classifica? } & \text { Boa } & 55 \% \\ & \text { Razoável } & 29,5 \% \\ & \text { Péssima } & 1,3 \%\end{array}$

$\begin{array}{llr}\text { Assinale dois fatores que influenciam na decisão } & \text { Preço e qualidade } & 67,6 \% \\ \text { de compra de hortaliças } & \text { Qualidade e facilidade } & 10,8 \% \\ & \text { Origem do produto e preço } & 14,9 \% \\ & \text { Preço e facilidade } & 5,4 \% \\ & \text { Faz bem para a saúde } & 0,7 \% \\ & \text { Não souberam responder } & 0,7 \%\end{array}$

Gasto médio com verdura por compra (para toda a família)
Menos de dez reais

Entre 11 e 20 reais

Entre 21 e 30 reais $27,3 \%$

Entre 31 e 40 reais $16,7 \%$

Acima de 40 reais $20,7 \%$

Menos de dez reais $12,1 \%$

Entre 11 e 30 reais $40,9 \%$

Entre 31 e 50 reais $28,9 \%$

Entre 51 e 60 reais $8,7 \%$

Acima de 61 reais
$9,4 \%$

Fonte: Autores.

Ao analisar os impactos da pandemia COVID-19 e sua interferência no consumo de vegetais, 90,2\% dos entrevistados afirmaram que não deixaram de consumir vegetais e os demais 9,8\% disseram que sim. Dentre as pessoas que relataram interferência no consumo de hortaliças, $32,7 \% \%$ delas diminuíram o consumo em menos de 5\%, 34,7\% diminuíram entre 6 a $10 \%, 10,2 \%$ entre 11 a 20\%,12,2\% entre 21 a $30 \%$ e 10,2\% reduziram mais que $31 \%$ no consumo de vegetais. Apesar da maior parte afirmarem continuar consumindo vegetais durante a quarentena, alguns relataram redução na frequência de consumo, devido ao isolamento social e medidas de proteção ao COVID-19, deixando muitos de saírem de casa para realizar a compra dos vegetais com constante frequência. Dentre os entrevistados que afirmaram ter ocorrido interferência no consumo de vegetais na 
pandemia, a maioria diz que a redução foi menor que 10\% (Figura 5). Malta et al. (2020), buscando caracterizar a relação da pandemia e a mudança no estilo de vida dos brasileiros adultos, verificou em seu trabalho que houve pequena redução no consumo de verduras e legumes durante a pandemia, já o consumo de frutas e feijão não houve alteração.

Figura 5 - Dados dos consumidores de hortaliças do município de Xinguara do estado do Pará. A) Interrupção do consumo de vegetais decorrente da COVID-19; B) Interferência total do consumo das pessoas que deixaram de consumir vegetais devido a COVID-19.

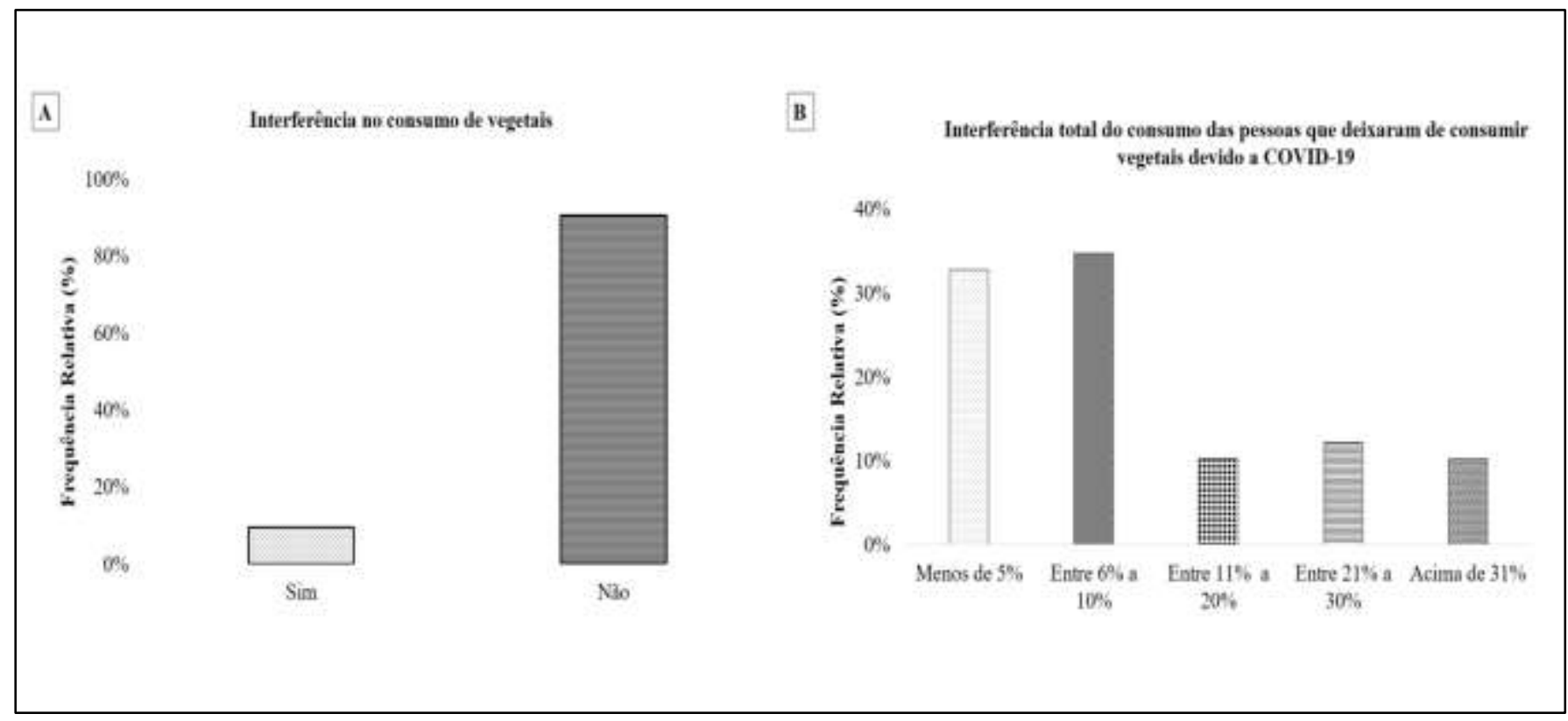

Fonte: Autores.

Quanto a renda familiar, 16,7 dos entrevistados possuem renda menor que um salário mínimo, 54,2\% entre 1 a 2 salários mínimos, 22,2 \% entre 2 a 4 salários mínimos e 6,9\% acima de 4 salários mínimos. Ao analisar a renda familiar dos entrevistados e sua participação na renda da família, obteve-se que 18,2\%\% não trabalham e recebem ajuda financeira da família, $12,8 \% \%$ trabalham e recebem ajuda financeira da família, 14,9\% trabalham e não recebem ajuda financeira da família, 33,8\% trabalham e contribuem parcialmente para o sustento da família e 20,3\% são responsáveis pelo sustento da família (Tabela 8). Resultado semelhante ao encontrado por Alves et al. (2014) no complexo do Ver-o-Peso do município de Belém-PA, onde a renda familiar da maior parte dos consumidores de hortaliças equivale entre um a dois salários mínimos. 
Tabela 8 - Renda familiar e participação dos entrevistados na renda familiar dos consumidores de hortaliças $(\mathrm{n}=150)$ nos municípios de Xinguara e microrregiões do sudeste Paraense.

\begin{tabular}{|c|c|c|}
\hline \multirow[t]{4}{*}{ Renda Familiar } & Menos de 1 salário mínimo & $16 \%$ \\
\hline & Entre 1 a 2 salários mínimos & $54 \%$ \\
\hline & Entre 2 a 4 salários mínimos & $22,7 \%$ \\
\hline & Acima de 4 salários mínimos & $7,3 \%$ \\
\hline \multirow[t]{5}{*}{ Qual sua participação na renda familiar } & $\begin{array}{l}\text { Não trabalha, porém recebe auxílio } \\
\text { financeiro da família }\end{array}$ & $18,2 \%$ \\
\hline & $\begin{array}{l}\text { Trabalha e recebe ajuda financeira da } \\
\text { família }\end{array}$ & $12,8 \%$ \\
\hline & $\begin{array}{l}\text { Trabalha e não recebe ajuda financeira da } \\
\text { família }\end{array}$ & $14,9 \%$ \\
\hline & $\begin{array}{l}\text { Trabalha e contribui parcialmente para o } \\
\text { sustento da família }\end{array}$ & $33,8 \%$ \\
\hline & É responsável pelo sustento da família & $20,3 \%$ \\
\hline
\end{tabular}

Fonte: Autores.

\section{Conclusão}

Neste trabalho podemos associar que a agricultura familiar possui êxito, pois a maioria dos agricultores entrevistados possuem a produção concentrada na zona urbana o que facilita o escoamento da produção para os supermercados, hortifrutigranjeiros, feira-livre e ao acesso do consumidor com a produção em si, o que transmite uma maior confiança em relação a qualidade de saneamento na produção.

Quanto ao perfil socioeconômico dos produtores, a renda bruta familiar é baixa, implicando diretamente no acesso a assistência técnica especializa, impossibilitando a produção de outras variedades de vegetais como foi relatado por um dos entrevistados que a produção é limitada apenas as culturas que são mais comuns e que possuem o conhecimento de produção repassado através das gerações familiares. A produção e as vendas dos vegetais durante a pandemia da COVID-19 tiveram uma queda de $60 \%$ no primeiro trimestre (março a maio de 2020), uma vez que todo o estado do Pará entrou em lockdown e algumas atividades foram suspensas como por exemplo as feiras-livres. Os supermercados são os estabelecimentos onde a maior parte dos consumidores adquirem as hortaliças, evidenciando que grande parte dos produtos adquiridos são oriundos de grandes produtores rurais, com plantações em mais de um hectare da propriedade.

Outro fator relevante observado neste estudo foi em relação ao gasto médio com verduras está ligado diretamente com a quantidade de membros nas famílias, a renda familiar e os hábitos de consumo que foi verificado que o consumo de verduras está diretamente ligado a renda familiar, pois quanto maior o poder aquisitivo da família maior é o consumo das verduras. O preço e qualidade dos vegetais são fatores que influenciam diretamente na compra das hortaliças, uma vez que a maioria dos entrevistados possuem entre um a dois salários mínimos de renda familiar, implicando diretamente no consumo de alimentos mais saudáveis. 
Com o início da pandemia da Covid-19, a maior parte da população entrevistada não deixou de consumir os vegetais, porém as compras foram realizadas em menor frequência devido ao isolamento social e a preocupação na hora de adquirir os produtos.

\section{Agradecimentos}

As autoras agradecem a Pró-Reitoria de Pós-Graduação, Pesquisa e Inovação Tecnológica e Pró-Reitoria de Extensão e Assuntos Estudantis da Universidade Federal do Sul e Sudeste do Pará pelo apoio.

\section{Referências}

Alves, R. J. M., Souza, L. P. F., Pontes, A. N (2014). Perfil socioeconômico e satisfação dos consumidores de produtos hortifrutículas do complexo do ver-opeso, Pará. Enciclopédia biosfera, Centro Científico Conhecer, 10 (19), 2912-2920. https://conhecer.org.br/ojs/index.php/biosfera/article/view/2513

Alves, V. O., Vieira, N. S., Silva, T. C., Ferreira, P. R (2011). O Associativismo na agricultura familiar dos estados da Bahia e Minas Gerais: potencialidades e desafios frente ao programa de aquisição de alimentos (PAA). Administração Pública e Gestão Social, 3 (1) 66-88. https://locus.ufv.br//handle/123456789/13336

Amor, A. L. M., Silva, R. M., Silva, A. A. M. R., Araújo, W. C., Oliveira, A. J., Almeida, J. S., Silva, A. S., Rocha, E. V. S., Rebouças, L. T., Silva, I. M. M (2012). Perfil de manipuladores e consumidores de hortaliças provenientes de feiras livres e supermercados. Revista Baiana de Saúde Pública, 36 (3).792-815. https://pesquisa.bvsalud.org/portal/resource/pt/lil-670709

Castro, R. R. A. \& Oliveira, M. C. C (2015). Cultivo e beneficiamento de mandioca (Manihot esculenta Crantz.) em comunidades tradicionais da Reserva Extrativista Rio Xingu, Terra do Meio, Pará, 2015. In: CONGRESSO BRASILEIRO DE AGROECOLOGIA, 9. Revista Cadernos de Agroecologia, 10 (3). http://revistas.aba-agroecologia.org.br/index.php/cad/article/view/18001/13363

Carvalho, D. C. M., \& Monteiro, M. S. L (2015). (Des) Construção teórica da agricultura familiar. OKARA,. 9 (1), 134-143. https://periodicos.ufpb.br/index.php/okara/article/view/19177/13411

Couto, V. A., Reis, L. L. M., Silva. E. M (2017). Pluriatividade e renda familiar no projeto de assentamento são Jorge e são José (PASJ), região cacaueira, BAHIA. Revista Macambira, 1 (1), 52. doi.org//10.35642/rm.vlil.105

Cruz, P.P., Moreira, G.R., Ferreira, F.S., Rodrigues, M.G (2010). Perfil socioeconômico dos produtores de hortaliças no município de Bom Jesus, Piauí, Brasil. Horticultura Brasileira, 28 (2), 455-460. http://www.abhorticultura.com.br/EventosX/Trabalhos/EV_4/A2841_T5071_Comp.pdf

Francilino, A. H., Gondim, A. R. O., Silva, F. F., Silva, J. L. B., Silva, Y. A (2014). Perfil dos consumos de hortaliças no município de iguatu-CE. Revista Verde, 9 (1), 120-126. https://www.gvaa.com.br/revista/index.php/RVADS/article/view/2619

Freitas, W. \& Wander, A.E (2017). O perfil socioeconômico da agricultura familiar produtora de hortaliças em Anápolis (GO, Brasil). Revista de Economia da $U E G, 13$ (1), 192-213. https://www.revista.ueg.br/index.php/economia/article/view/5882

Guerra, A. M. N. M., Santos, D. S., Silva, P. S., Santos, L. B. (2018) Perfil dos consumidores e comerciantes de hortaliças em feira livre na cidade de Barra BA. Tecnologia. \& Ciência Agropecuária, , 12 (4), 39-45. https://revistatca.pb.gov.br/edicoes/volume-12-2018/volume-12-n-4-2018/07-ce-0618-02-perfil-dosconsumidores-e-comerciantes-de-hortalicas.pdf

Honda, Y. F., Gomes, S. C., Cabral, R. E (2016). Agricultura Familiar em área periurbana do Munícipio de Ananindeua-PA: práticas e estratégias desenvolvidas, Horizonte Científico, seção Geografia, 10, (1). http://www.seer.ufu.br/index.php/horizontecientifico/article/view/33468

IBGE - Instituto Brasileiro de Geografia e Estatística (2012). Sidra: Sistema IBGE de recuperação automática. http://www.sidra.ibge.gov.br

IBGE - Instituto Brasileiro de Geografia e Estatística (2006). Sidra: Sistema IBGE de recuperação automática. http://www.sidra.ibge.gov.br/bda.

IBGE - Instituto Brasileiro de Geografia e Estatística (2017). Sidra: Sistema IBGE de recuperação automática. https://sidra.ibge.gov.br/pesquisa/censoagropecuario/censo-agropecuario-2017

Leite, G. M. \& Lopes, M. L. B. Agricultura Urbana: Análise da experiência desenvolvida na comunidade do Curuçambá. In: Tobias, M. S. G; Lima, A. C. (Orgs.) Urbanização \& Meio Ambiente. Belém: UNAMA, 2012. http://www6.unama.br/mestrado/desenvolvimento/attachments/arti cle/70/Urbaniza\%C3\%A7\%C3\%A3o\%20e\%20Meio\%20Ambiente\%20-\%20Vol.\%20I.pdf

Malta, D. C., Szwarcwald, C. L., Barros, M. B. A., Gomes, C. S., Machado, I. E., Júnior, P. R. B. S., Romero, D. E., Lima, M. G., Damacena, G. N., Pina, M. F., Freitas, M. I. F., Werneck, A. O., Silva, D. R. P., Azevedo, L. O., Gracie, R. A (2020). Pandemia da COVID-19 e as mudanças no estilo de vida dos brasileiros adultos: um estudo transversal, 2020. Epidemiologia e Serviços de Saúde, 29 (4). doi: 10.1590/S1679-49742020000400026

Mattos, L. M., Moretti C. L., Moura, M. A., Maldonade, I. R., Silva, E. Y. Y (2009). Produção segura e rastreabilidade de hortaliças. Horticultura Brasileira, 27 (4), 408-413. doi.org/10.1590/S0102-05362009000400002

Moreira, G. R., Cruz, P. P., Ferreira, F. S., Rodrigues, M. G (2012). Perfil dos compradores de hortaliças na feira livre de Bom Jesus-PI. Enciclopédia Biosfera, Centro Científico Conhecer, 8 (15), 2518. https://conhecer.org.br/ojs/index.php/biosfera/article/view/3810

Neta, M. L S., Silva, R. T., Souza, A. A. T., Pamplona, J. P., Oliveira, F. A., Oliveira, M. K. T (2013). Perfil dos consumidores de hortaliças do município de Apodi-RN. Agropecuária Científica no Semi-Árido, 9 (1), 50-56. http://revistas.ufcg.edu.br/acsa/index.php/ACSA/article/view/229 
Research, Society and Development, v. 10, n. 7, e55910716853, 2021

(CC BY 4.0) | ISSN 2525-3409 | DOI: http://dx.doi.org/10.33448/rsd-v10i7.16853

Ohse, S., Carvalho, M. S., Rezende, A. L. B., Oliveira, B. J., Manfron, A. A., Neto, D. D (2012). Produção e composição química de hortaliças folhosas em hidroponia. Bioscience Journal, 28 (2), 155-163. https://pesquisa.bvsalud.org/portal/resource/pt/biblio-912551?src=similardocs

Sá, M. E. R., Costa, S. M. G., Tavares, L. P. O (2006). O rural-urbano em Santarém: interfaces e territórios produtivos. In: CARDOSO, A. C. D. (Org.). O rural e o urbano na Amazônia: diferentes olhares em perspectivas. Belém: EDUFPA. https://www.observatoriodasmetropoles.net.br/o-rural-e-o-urbano/

Salazar, L., Schling, M., Palactos, A. C., Pazos, N (2020). Retos para la agricultura familiar en el contexto del Covid-19: Evidencia de Productores en ALC. Banco Interamericano de Desarrollo. doi.org/10.18235/0002453

Souza, L. J., \& Garcia, D.C.R (2013). Custos e rentabilidades na produção de hortaliças orgânicas e convencionais no estado do Espírito Santo. Revista Brasileira de Agropecuária Sustentável (RBAS), 3, (1), 11-24.

Sampaio, E. V. S. B (1995). Overview of the Brazilian caatinga. In: Stephen, H. B.; Mooney, H. A.; Medina, E. (Eds.) Seasonally dry tropical forests. Ed.Cambridge University. 35-63.

Sediyama, M., Garcia, N. C. P., Vidigal, S. M., Matos, A. T (2000). Nutrientes em compostos orgânicos de resíduos vegetais e dejeto de suínos. Scientia Agricola, 57 (1), 185-189. doi.org/10.1590/S0103-90162000000100030

Silva W. F., Marques, D. J., Silva, E. C., Bianchini, H. C., Ishimoto, F. A., Pereira, J. M. J. F (2015). Diagnóstico da produção de hortaliças na região metropolitana de Belo Horizonte. Horticultura Brasileira 33 (3), 368-372. doi.org/10.1590/S0102-053620150000300015

Silva, B. A., Silva, A. R., Pagiuca, L. G (2014). Hortifruti Brasil. https://www.cepea.esalq.usp.br/hfbrasil/edicoes/132/mat_capa.pdf

Silva, J. B. C., Lopes, C. A., Magalhães, J. S (2008). Como plantar batata-doce. Embrapa Hortaliças Sistemas de Produção. https://www.embrapa.br/hortalicas/batata-doce/introducao.

Souza, E. A., Barba, J. A., Barbosa, J. M. A., Ribeiro, G. F. F., Martins, M. L. B (2016). Consumo de frutas, verduras e legumes por adolescentes do Estado do Maranhão. Adolesc, Saúde, Rio de Janeiro, 13 (4), 33-41. http://adolescenciaesaude.com/detalhe_artigo.asp?id=623

Souza, R. S., Arbage, A. P., Neumann, P. S., Froehlich, J. M., Diesel, V., Silveira, P. R., Silva, A.; Corazza, C., Baumhardt, E., Lisboa, R. S (2008). Comportamento de compra dos consumidores de frutas, legumes e verduras na região central do Rio Grande do Sul. Ciência Rural, 38, (2). doi.org/10.1590/S0103-84782008000200034

Tofanelli, M. B. D., Fernandes, M. S., Filho, O. B. M., Carrijo, N. S (2007). Mercado de hortaliças frescas no município de Mineiros-GO. Horticultura Brasileira, 25, (3), 475-478. doi.org/10.1590/S0102-05362007000300030

Viana, J. S., Lourenço, M. S. N., Gomes, A. M. N., Alves, T. L., Filho, A. S. B. O (2020). Perfil dos Consumidores e Caracterização Química de Hortaliças Folhosas Comercializadas em Feiras Livres na Cidade de São Luís-MA. Revista Craibeiras de Agroecologia, 5 (1), 9255. https://www.seer.ufal.br/index.php/era/article/view/9255/7340 